\title{
Development of Manufacture Support System Using Taguchi Methods
}

\author{
Ikuo Tanabe \\ Professor, Department of Mechanical Engineering, \\ Nagaoka University of Technology, \\ 1603-1 Kamitomioka-machi, Nagaoka, Niigata, 940-2188 Japan \\ tanabe@mech.nagaokaut.ac.jp
}

\begin{abstract}
A Manufacture Support System using Taguchi Methods was developed and evaluated. This system consists of a Taguchi methods part, a CAE simulation part and a management part of productivity. The Taguchi methods part was firstly used for calculating the average and the standard deviation regarding all combinations using all parameters. The CAE part was then used for shortening the total time of evaluation. The management part of productivity was finally used to select the optimum combination of all parameters for success percentage, accuracy, manufacturing time and total cost. The spring back of warm press forming on magnesium alloy plate was investigated for evaluating this system. It is concluded from the result that (1) This method effectively predicted optimum process conditions in each priority and (2) The predicted results conformed to the results of the spring back test.
\end{abstract}

Keywords: Taguchi methods, Computer Integrated Manufacturing, CAE, Finite Element Method, Productivity, Management.

\section{Introduction}

Recently a developments with short-term and lower cost are strongly required for shorten products life cycle. Therefore FEM simulation is used for predicting the result of design process instead of doing experiments. On the other hand, Taguchi methods [1], [2], [3] is also used for deciding optimum process conditions. However these methods are not enough to develop a new product with high quality and accuracy.

In this study, a manufacture support system using Taguchi methods was developed and evaluated. Spring back of warm press forming on magnesium alloy plate was investigated for evaluating this system in the experiment.

\section{Explanation of Manufacture Support System}

Flow chart of the manufacture support system using Taguchi methods for products was shown in Fig.1. This system consists of a Taguchi methods part, a CAE simulation part and a management part of productivity.

Control and noise factors are shown in Table 1. These factors are used in the later experiment and are important factors in the Taguchi methods. Each factor has several 
levels. Control factors are equal to the design factors. Noise factors are occurred for the error of function on the product. Here, when the distribution data or many values for noise factors were used, SN ratios and sensitivity of the desired property or averages and standard deviations for all combinations of the control factors were calculated with very high accuracy. Then calculation accuracy of this system became very good. All combinations using all control factors are $4374\left(=6 \times 3^{6}\right)$ kinds for Table 1 , however these combinations were compressed to 18 kinds of orthogonal table in Table 2. Influence of the nose factors was investigated regarding $2^{5}$ times $(=2$ : maximum and minimum vales of each noise factor, 5: number of noise factor) for each combination of the control factors. Therefore number of the CAE calculations in this case was 576 times $\left(=18\right.$ kinds $\times 2^{5}$ times). SN ratio and Sensitivity were calculated by equations of (1) and (2).

\section{Start}

\section{Part I}

Input : $\cdot$ Control factors and these levels

- Noise factors and these levels

- Averages and standard deviations of noise factors

- Control factors were arranged in an orthogonal array.

- This is compression of trial number.

- $\mathrm{SN}$ ratios and sensitivity of the desired property were calculated for the all combinations of the control factors.

- Averages and standard deviations for all combinations of the control factors were calculated.

- The desired property was calculated by CAE simulation with the orthogonal array, and back to the Taguchi methods path.

- Distributions of the desired property were calculated for all combination of the control factors by the averages and standard deviations.

Input: Data for productivity management

- Ordering condition $\cdot$ Productivity condition $\cdot$ Priority

Calculation of the productivity management factors:

- Non-defective unit rate $\cdot$ Number of product

-All time for manufacturing of the product - Total cost

Priority output:

Optimum combination and optimum productivity management factors were outputted from all combinations of the control factors.

\section{End}

Fig. 1. Flow chart of the manufacture support system using Taguchi methods 
Table 1. Control and noise factors

\begin{tabular}{|c|c|c|c|c|c|c|c|c|}
\hline \multirow{9}{*}{$\begin{array}{l} \\
0 \\
0 \\
0 \\
0 \\
0 \\
\frac{0}{0} \\
\frac{\pi}{0} \\
0 \\
0 \\
0 \\
0 \\
0\end{array}$} & \multirow{2}{*}{\multicolumn{2}{|c|}{$\begin{array}{r}\text { Levels } \\
\text { a: Tension (MPa) }\end{array}$}} & 1 & 2 & 3 & 4 & 5 & 6 \\
\hline & & & 10 & 50 & 90 & 130 & 170 & 210 \\
\hline & & Levels & \multicolumn{2}{|c|}{1} & \multicolumn{2}{|c|}{2} & \multicolumn{2}{|c|}{3} \\
\hline & \multicolumn{2}{|c|}{ b: Punch speed (mm/min) } & \multicolumn{2}{|c|}{150} & \multicolumn{2}{|c|}{300} & \multicolumn{2}{|c|}{500} \\
\hline & \multicolumn{2}{|c|}{ c: Temperature of die $\left({ }^{\circ} \mathrm{C}\right)$} & \multicolumn{2}{|c|}{150} & \multicolumn{2}{|c|}{200} & \multicolumn{2}{|c|}{250} \\
\hline & \multicolumn{2}{|c|}{ d: Lublicant } & \multicolumn{2}{|c|}{ Teflon } & \multicolumn{2}{|c|}{ Lub. C } & \multicolumn{2}{|c|}{ Lub. D } \\
\hline & \multicolumn{2}{|c|}{ e: Test piece } & \multicolumn{2}{|c|}{ Mat. M } & \multicolumn{2}{|c|}{ Mat. O } & \multicolumn{2}{|c|}{ Mat. Ob } \\
\hline & \multicolumn{2}{|c|}{$\mathrm{f}:$ Die radious $(\mathrm{mm})$} & \multicolumn{2}{|c|}{6} & \multicolumn{2}{|c|}{8} & \multicolumn{2}{|c|}{10} \\
\hline & \multicolumn{2}{|c|}{$\mathrm{g}:$ Clearance $(\mathrm{mm})$} & & & \multicolumn{2}{|c|}{10} & \multicolumn{2}{|c|}{15} \\
\hline \multirow{6}{*}{$\begin{array}{l}\frac{\infty}{0} \\
\frac{0}{0} \\
\mathbb{0} \\
\mathbb{\infty} \\
\frac{\mathscr{N}}{0} \\
Z\end{array}$} & & Levels & & 1 & & & 2 & \\
\hline & Blank ho & ding force $(\%)$ & & -10 & & & +10 & \\
\hline & Tempera & ture of die (\%) & & -5 & & & +5 & \\
\hline & \multirow{3}{*}{$\begin{array}{c}\text { k value } \\
※ 1\end{array}$} & Mat. M (\%) & \multicolumn{3}{|c|}{-1.5} & \multicolumn{3}{|c|}{+1.5} \\
\hline & & Mat. O (\%) & \multicolumn{3}{|c|}{-3} & \multicolumn{3}{|c|}{+3} \\
\hline & & Mat. Ob (\%) & \multicolumn{3}{|c|}{-10} & \multicolumn{3}{|c|}{+10} \\
\hline
\end{tabular}

$※ 1 \mathrm{k}$ : Work hardening coefficient

Table 2. Orthogonal table

\begin{tabular}{|c|c|c|c|c|c|c|c|}
\hline & \multicolumn{7}{|c|}{ Control factors } \\
\hline & $\begin{array}{c}\text { a: } \\
\text { Tension } \\
\text { Mpa }\end{array}$ & $\begin{array}{c}\text { b: } \\
\text { Punch } \\
\text { speed } \\
\mathrm{mm} / \mathrm{min}\end{array}$ & $\begin{array}{l}\text { C: } \\
\text { Temp. } \\
\text { of die } \\
{ }^{\circ} \mathrm{C}\end{array}$ & $\begin{array}{c}\mathrm{d}: \\
\text { Lublicant }\end{array}$ & $\begin{array}{c}\mathrm{e}: \\
\text { Test } \\
\text { piece }\end{array}$ & $\begin{array}{c}\mathrm{f}: \\
\text { Die radius } \\
\mathrm{mm}\end{array}$ & $\begin{array}{c}\text { g: } \\
\text { Clearance } \\
\text { mm }\end{array}$ \\
\hline 1 & 10 & 150 & 150 & Teflon & Mat. M & 6 & 5 \\
\hline 2 & 10 & 300 & 200 & Lub. C & Mat. $O$ & 8 & 10 \\
\hline 3 & 10 & 500 & 250 & Lub. D & Mat. $\mathrm{Ob}$ & 10 & 15 \\
\hline 4 & 50 & 150 & 150 & Lub. C & Mat. O & 10 & 15 \\
\hline 5 & 50 & 300 & 200 & Lub. D & Mat. Ob & 6 & 5 \\
\hline 6 & 50 & 500 & 250 & Teflon & Mat. M & 8 & 10 \\
\hline 7 & 90 & 150 & 200 & Teflon & Mat. $\mathrm{Ob}$ & 8 & 15 \\
\hline 8 & 90 & 300 & 250 & Lub. C & Mat. M & 10 & 5 \\
\hline 9 & 90 & 500 & 150 & Lub. D & Mat. O & 6 & 10 \\
\hline 10 & 130 & 150 & 250 & Lub. D & Mat. O & 8 & 5 \\
\hline 11 & 130 & 300 & 150 & Teflon & Mat. Ob & 10 & 10 \\
\hline 12 & 130 & 500 & 200 & Lub. C & Mat. M & 6 & 15 \\
\hline 13 & 170 & 150 & 200 & Lub. D & Mat. M & 10 & 10 \\
\hline 14 & 170 & 300 & 250 & Teflon & Mat. O & 6 & 15 \\
\hline 15 & 170 & 500 & 150 & Lub. C & Mat. Ob & 8 & 5 \\
\hline 16 & 210 & 150 & 250 & Lub. C & Mat. Ob & 6 & 10 \\
\hline 17 & 210 & 300 & 150 & Lub. D & Mat. M & 8 & 15 \\
\hline 18 & 210 & 500 & 200 & Teflon & Mat. O & 10 & 5 \\
\hline
\end{tabular}




$$
\begin{gathered}
\text { SN ratio }(\mathrm{db})=10 \log \left(\mu^{2} / \sigma^{2}\right) \\
\text { Sensitivity }(\mathrm{db})=10 \log \mu^{2}
\end{gathered}
$$

Where $\mu$ is average of the evaluation value, and $\sigma$ is standard deviation of the evaluation value in the results of CAE. The evaluation vale is the spring back in the later CAE simulation. Then most of users write the effective figure of the control factors and zealously search the combination of the control factors for little SN ratio. A product using the combination isn't influenced by noise factors.

The CAE part was then used for shortening the total time of evaluation regarding the design factors of the development. The CAE part is a sub program for the part of Taguchi methods. This simulation can calculate much behavior; those are static, dynamic and thermal behaviors, vibration, flow of a fluid, large deformation such as cutting, press forming, crash or explosion. The control factors in the Taguchi methods can directly input to the CAE simulation. With regard to the noise factors in the Taguchi methods, it also can input directly or the properties of dependence on temperature, time or boundary conditions.

At last, the average and the standard deviation regarding all combinations using all parameters are calculated by the SN ratio and Sensitivity with 18 kinds. The addition theorem in the Taguchi methods was used for calculating the results for all combinations. For example, when $m$ is a control factor and $n$ is the level for the factor, the SN ratio $S N_{m n}$ and Sensitivity $S_{m n}$ for the control factor $m$ and the level $n$ are calculated by the addition theorem. Moreover the $\mathrm{SN}$ ratio $S N_{\mathrm{a} 4} \cdot \mathrm{b} 2 \cdot \mathrm{c} 1 \cdot \mathrm{d} 3 \cdot \mathrm{e} 2 \cdot \mathrm{f} 1 \cdot \mathrm{g} 2$ and the Sensitivity $S_{\mathrm{a} 4 \cdot \mathrm{b} 2 \cdot \mathrm{c} 1 \cdot \mathrm{d} 3 \cdot \mathrm{e} 2 \cdot \mathrm{f} 1 \cdot \mathrm{g} 2}$ for a4, b2, c1, d3, e2, f1, g2 using control factors (a, b, c, d, e, f, and g) and levels (1, 2, 3, 4, 5 and 6) were calculated by the equations (3) and (4), respectively.

$$
\begin{aligned}
& S N_{\mathrm{a} 4} \cdot \mathrm{b} 2 \cdot \mathrm{c} 1 \cdot \mathrm{d} 3 \cdot \mathrm{e} 2 \cdot \mathrm{f} 1 \cdot \mathrm{g} 2=S N_{\mathrm{a} 4}+S N_{\mathrm{b} 2}+S N_{\mathrm{c} 1}+S N_{\mathrm{d} 3}+S N_{\mathrm{e} 2}+S N_{\mathrm{f} 1}+S N_{\mathrm{g} 2} \\
&-(7-1) S N_{\mathrm{ave}} \\
& S_{\mathrm{a} 4 \cdot \mathrm{b} 2 \cdot \mathrm{c} 1 \cdot \mathrm{d} 3 \cdot \mathrm{e} 2 \cdot \mathrm{f} 1 \cdot \mathrm{g} 2}=S_{\mathrm{a} 4}+S_{\mathrm{b} 2}+S_{\mathrm{c} 1}+S_{\mathrm{d} 3}+S_{\mathrm{e} 2}+S_{\mathrm{f} 1}+S_{\mathrm{g} 2} \\
&-(7-1) S_{\mathrm{ave}}
\end{aligned}
$$

Where $S N_{\text {ave }}$ and $S_{\text {ave }}$ are each average of the all SN ratio and the all Sensitivity, respectively.

This method has several features; it can reduce the trial numbers in the CAE simulation, it can show the influence of the error factors and it can quickly calculate all of the results regarding all combinations of all parameters.

The management part of productivity was finally used for selecting the optimum value regarding all parameters. This part received both the average and the standard deviation for all combinations of all parameters on the Taguchi methods part, the all frequencies of occurrence are then calculated by the cumulative distribution function with the average and the standard deviation. A cumulative distribution function is shown in Fig. 2. If the tolerance $\eta_{\mathrm{tol}}$ is decided, non-defective unit rate $G$ is calculated by the cumulative distribution function [4] such as equation (5).

$$
\begin{aligned}
& G=\mathrm{f}\left(\eta_{\mathrm{tol}}, \mu, \sigma\right) \\
& N=N_{\text {ord }} / G
\end{aligned}
$$




$$
\begin{gathered}
T_{\mathrm{m}}=\Sigma^{\text {(from } 1 \text { to final machine number) }} T_{\mathrm{V}} \\
T_{\mathrm{a} 1 \mathrm{l}}=N T_{\mathrm{m}} \\
C_{\mathrm{a} 11}=\left(C_{\text {mat }}+C_{\text {was }}+C_{\mathrm{dis}}(1-G)+C_{\mathrm{m} \text {-pri }}\right) N+T_{\mathrm{all}} C_{\mathrm{m}}
\end{gathered}
$$

When number $N$ of all products is calculated by using the order entry $N_{\text {ord }}$ and the non-defective unit rate $G$ such as equation (6), the working time $T_{\mathrm{V}}$ for the machine tool $V$ is calculated by each machine tool, the number of all products $N$, machining condition, the arrangement time and the progress of the work. The working time $T_{\mathrm{m}}$ for the product is calculated by the equation (7), total working time $T_{\text {all }}$ is calculated by the working time $T_{\mathrm{m}}$ and number $N$ of all products such as equation (8), and unit cost of material is $C_{\text {mat }}$, unit cost of consumption article is $C_{\text {was }}$, waste cost for inferior goods is $C_{\mathrm{dis}}$, amortize cost of the used machine tools for the product is $C_{\mathrm{m} \text {-pri }}$ and labor cost for one hour is $C_{\mathrm{m}}$, Total production cost is calculated by the equation (9).

The order condition and the cost table are shown in Table 3. This is the data for the later evaluation on the press. Then the optimum combination of the control factor for the priority item was decided. The priority items are success percentage, accuracy, manufacturing time or total cost. At that time, the designer can select the priority in the productivity factors on the design stage.

$\sigma:$ Standard deviation

Non-defective unit rate

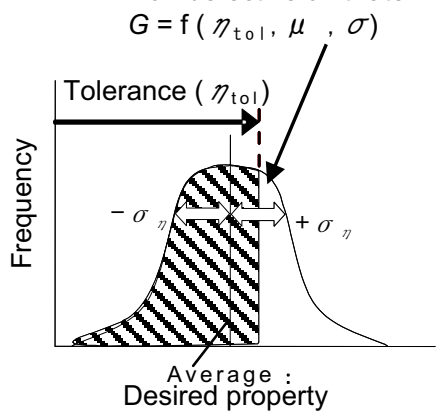

\begin{tabular}{|c|c|c|c|}
\hline \multirow{3}{*}{ 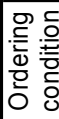 } & \multicolumn{2}{|l|}{ Tolerance } & 0.01 \\
\hline & \multicolumn{2}{|l|}{ Order entry (unit) } & 1000 \\
\hline & \multicolumn{2}{|c|}{ Delivery (hour) } & 24 \\
\hline \multirow{8}{*}{ 范 } & \multirow{3}{*}{$\begin{array}{l}\text { Magunesium } \\
\text { sheet }\end{array}$} & Mat.M (yen / unit) & 260 \\
\hline & & Mat.O (yen / unit) & 180 \\
\hline & & Mat.Ob (yen / unit) & 180 \\
\hline & \multirow{3}{*}{ Lublicant } & Teflon (yen / unit) & 50 \\
\hline & & Lub.D (yen / unit) & 0.0531 \\
\hline & & Lub.C (yen / unit) & 0.304 \\
\hline & \multicolumn{2}{|c|}{ Disposal cost (yen / unit) } & 2.16 \\
\hline & \multicolumn{2}{|c|}{ Charge rate (yen / hour) } & 2000 \\
\hline
\end{tabular}

Fig. 2. Cumulative distribution function
Table 3. Order condition and cost table

\section{Evaluation Using Spring Back on Press of Magnesium Alloy}

CAE and an experiment using the press of magnesium alloy were performed for evaluation of this system. Experimental set-up of press with AZ31 magnesium alloy was shown in Fig.3 [5]. This evaluation was used a spring back such as Fig. 4. This value became the desired value in our system. Simulation model for the CAE was shown in Fig.5. This is a quarter model of the experimental set-up. The control factor and the noise factor in Table 1 were input data of the CAE. Data of the management for productivity was shown in Table 3. This is important data for deciding the optimum condition of the design. 
Results of evaluation for this system are shown in Table 4. These results are the each priority for accuracy, total cost, manufacturing time or non-defective unit rate. The optimum combination using the control factors and its levels for each priority are also shown in Table 4. These were each best combination for the priority item. The experiment for evaluation of the calculation accuracy was performed by using the spring-back. Spring-backs in the experiment are between 0.1 and 0.5 . Therefore the combinations of the control factors for 0.1 spring-back (=Best condition) for 0.5 spring back (=Worst condition) were experimented. The SN ratio and the Sensitivity for both the best and worst conditions are shown in Table 5. And gain deference between the prediction using our system and the experimental results are shown in the Table 6. The predictions using our system are equal to the results of the experiment. Therefore our system will be used for calculating the optimum conditions at the design stage.

Twice examples using this system were also shown in Table 7. These are the best condition for the cost or the time both before and after change of the test piece. When you must use the only Test piece: 3 (=Mat $\mathrm{O}_{\mathrm{b}}$ with large dispersion of the property),

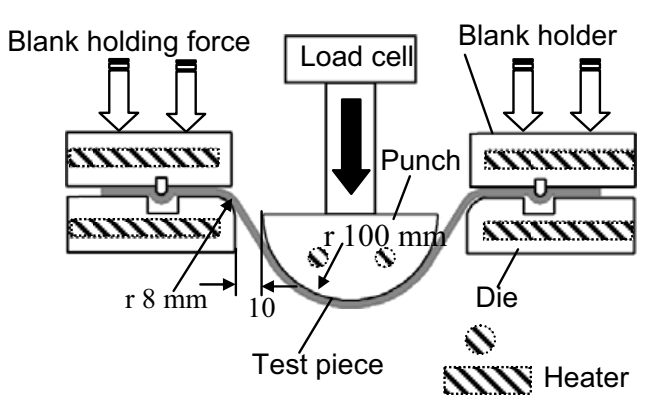

Fig. 3. Schematic view of spring-back testing mold

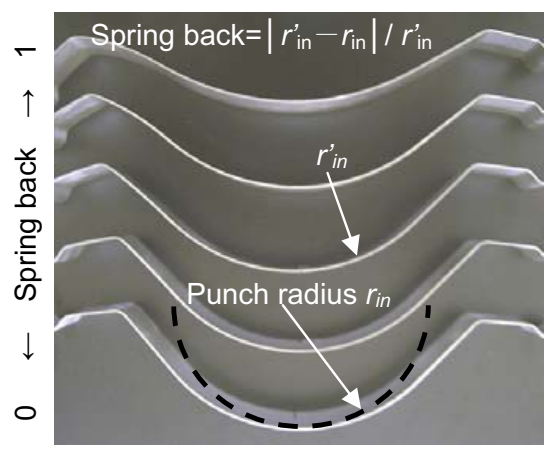

Fig. 4. Spring back

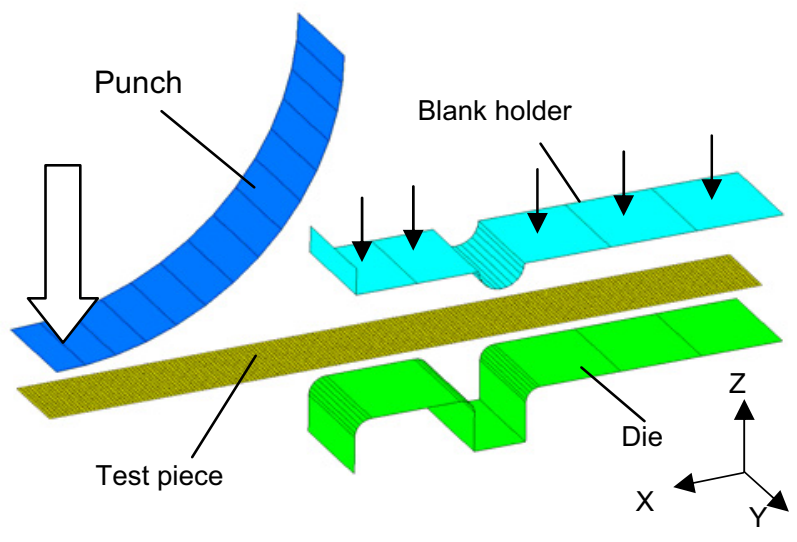

Fig. 5. Simulation model for the CAE (A quarter model) 
Table 4. Result of evaluation for this system

\begin{tabular}{|c|c|c|c|c|c|}
\hline & Priority item & $\begin{array}{c}\text { Spring back } \\
\eta_{\text {ave }}\end{array}$ & $\begin{array}{c}\text { Total cost } \\
C_{\text {all }}\end{array}$ & $\begin{array}{c}\text { Total time } \\
T_{\text {all }}\end{array}$ & $\begin{array}{c}\text { Non defective } \\
\text { unit rate } \\
G\end{array}$ \\
\hline \multirow{7}{*}{ 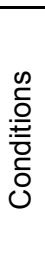 } & a: Tension & 5 & 5 & 5 & 5 \\
\hline & b: Punch speed & 2 & 2 & 3 & 2 \\
\hline & C: Temp. of die & 2 & 2 & 2 & 2 \\
\hline & d: Lublication & 1 & 3 & 1 & 1 \\
\hline & e: Test piece & 2 & 2 & 2 & 2 \\
\hline & f: Die-radius & 3 & 3 & 3 & 3 \\
\hline & g: Clearance & 1 & 1 & 3 & 3 \\
\hline \multirow{5}{*}{ 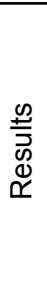 } & Spring-back & 0.0039 & 0.0091 & 0.0071 & 0.0042 \\
\hline & $\begin{array}{l}\text { Non defective unit } \\
\text { rate (\%) }\end{array}$ & 100 & 97 & 99 & 100 \\
\hline & $\begin{array}{l}\text { Number of } \\
\text { processing (unit) }\end{array}$ & 1000 & 1029 & 1013 & 1000 \\
\hline & Total time (hour) & 7.8 & 8.0 & 4.7 & 7.8 \\
\hline & $\begin{array}{l}\text { Total cost } \\
\text { (10000yen) }\end{array}$ & 24.6 & 20.2 & 24.2 & 24.6 \\
\hline
\end{tabular}

Best result

Table 5. Machining conditions for confirmation experiment

\begin{tabular}{|c|c|c|c|}
\hline & Best & Worst \\
\hline \multirow{4}{*}{ 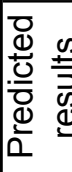 } & Spring-back & 0.09 & 0.45 \\
\hline & Std. deviation & 0.007 & 0.100 \\
\hline & SN ratio $(\mathrm{db})$ & 22.18 & 13.03 \\
\hline & Sensitivity (db) & -20.92 & -6.94 \\
\hline \multirow{7}{*}{ 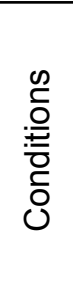 } & a: Tension & 6 & 2 \\
\hline & b: Punch speed & 1 & 2 \\
\hline & c: Temperature of die & 3 & 3 \\
\hline & d: Lublicant & 2 & 1 \\
\hline & e: Tesit piece & 1 & 1 \\
\hline & f: Die-radius & 2 & 2 \\
\hline & g: Clearance & 2 & 2 \\
\hline
\end{tabular}

Table 6. Comparison results between prediction and experiment

\begin{tabular}{|c|c|c|c|c|}
\hline \multicolumn{2}{|c|}{} & Best condition & Worst condition & Gain \\
\hline $\begin{array}{c}\text { SN ratio } \\
(\mathrm{db})\end{array}$ & Prediction & 22.18 & 13.03 & 9.15 \\
\cline { 2 - 5 } & Experiment & 22.06 & 12.98 & 9.08 \\
\hline $\begin{array}{c}\text { Sensitivity } \\
(\mathrm{db})\end{array}$ & Prediction & -20.92 & -6.94 & -13.98 \\
\cline { 2 - 5 } & Experiment & -20.92 & -9.12 & -11.80 \\
\hline
\end{tabular}


Table 7. Change of condition by improvement

\begin{tabular}{|c|c|c|c|c|c|}
\hline \multirow{2}{*}{\multicolumn{2}{|c|}{$\begin{array}{l}\text { Priority item } \\
\text { Improvement }\end{array}$}} & \multicolumn{2}{|c|}{$\begin{array}{c}\text { Total cost } \\
C_{\text {all }}\end{array}$} & \multicolumn{2}{|c|}{$\begin{array}{c}\text { Total time } \\
T_{\text {all }}\end{array}$} \\
\hline & & Before & After & Before & After \\
\hline \multirow{7}{*}{ 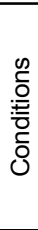 } & a: Tension & 5 & 5 & 5 & 5 \\
\hline & b: Punch speed & 2 & 2 & 3 & 2 \\
\hline & c: Temp. of die & 2 & 2 & 2 & 2 \\
\hline & d: Lublication & 3 & 1 & 1 & 1 \\
\hline & e: Test piece & \multicolumn{4}{|c|}{3} \\
\hline & f: Die-radius & 3 & 3 & 3 & 3 \\
\hline & g: Clearance & 1 & 3 & 3 & 3 \\
\hline \multirow{6}{*}{ 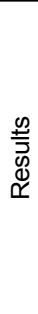 } & Spring-back & 0.0145 & 0.0067 & 0.0113 & 0.0067 \\
\hline & $\begin{array}{l}\text { Non defective unit } \\
\text { rate }(\%)\end{array}$ & 0.02 & 96 & 36 & 96 \\
\hline & \begin{tabular}{|l|} 
Number of \\
processing (unit)
\end{tabular} & 6087694 & 1045 & 2806 & 1045 \\
\hline & $\begin{array}{l}\text { Forming time } \\
\text { (sec/parts) }\end{array}$ & 28.0 & 28.0 & 16.8 & 28.0 \\
\hline & Total time (hour) & 47348.0 & 8.1 & 13.1 & 8.1 \\
\hline & \begin{tabular}{|l|} 
Total cost \\
(10000yen)
\end{tabular} & 120548.0 & 25.7 & 67.5 & 25.7 \\
\hline
\end{tabular}

you should change the conditions in Table 4. At that time, this system can swiftly calculate the optimum condition in several condition changes. Therefore this system was very useful for manufacture.

\section{Conclusion}

It is concluded from the result that;

(1) The manufacture support system using Taguchi methods was manufactured.

(2) The proposed method predicted optimum processing conditions effectively in each priority.

(3) The predicted results conformed to the results of the actual spring back test.

\section{References}

1. Makino, T.: Optimization of Exhaust Port using Computer Simulation. In: Proceedings of the 13th Quality Engineering Society Conference, pp. 6-9 (2005)

2. Fujikawa, S.: Optimum Parameter Design using the Taguchi methods for Finite-Element Analysis of 3D Forging Deformation. Journal of the Japan Society of Technology, for Plasticity 40(466), 1061-1065 (1999)

3. Tatebayashi, K.: Computer Aided Engineering Combined with Taguchi methods. In: Proceeding of the 2005 Annual Meeting of the Japan Society of Mechanical Engineering, vol. 8, No. 05-1, pp. 224-225 (September 2005)

4. Nagakura, S., et al.: Iwanami Physics and Chemistry Dictionary, Iwanami Shoten, p. 1234 (1988) (in Japanese)

5. Sugai, H., et al.: Prediction of Optimum Machining Condition in Press Forming Using Taguchi methods and FEM Simulation. Transactions of the JSME 72(721), 3044-3051 (2006) (in Japanese) 